\title{
Testing and developing a wetland assessment index in southeast Australia using aquatic plants
}

\author{
J. E. Ling ${ }^{1}$ and S. W. L. Jacobs ${ }^{2 \dagger}$ \\ ${ }^{1}$ New South Wales Department of Environment Climate Change and Water Sydney, \\ NSW Australia \\ ${ }^{2}$ National Herbarium of New South Wales, Mrs Macquaries Rd, Sydney, NSW 2000, Australia \\ Author for correspondence: joanne.ling@environment.nsw.gov.au
}

\begin{abstract}
The vegetation-based Hawkesbury-Nepean Wetland Assessment (HNWA) Index developed by Sainty and Jacobs (1997), was evaluated using three years of field survey data. Twenty-one wetlands that varied in geomorphology, dominant vegetation, hydrology, substrate and degree of human impact were assessed. Data from these wetlands were used to investigate the influence that taxonomic resolution (plant identification to family, genus or to lower ranks), species inclusion (all species recorded or only aquatic species recorded), spatial and temporal variability, cover class and scaling had on overall performance of the index. A modified water plant index was developed that is simpler and has a wider geographic application than other options available in Australian for on-ground wetland condition assessment using aquatic plants. Application of real data to the index highlighted the cumulative effects of error on summarising data into a single index and compounding effects to multimetric situations.
\end{abstract}

\section{Introduction}

Aquatic plants can be used to monitor the condition of wetlands because they are key to trophic level dynamics within any wetland ecosystem. Indices or metrics of wetland condition based on plants, however, have had limited use compared to indices using macroinvertebrates. The most widely applied techniques for assessing the health or condition of freshwater ecosystems typically use: (1) a single index; (2) multiple indices; or (3) predictive modelling algorithms. These three techniques have been developed and used extensively using macroinvertebrate diversity and abundance. Wetland assessment based on aquatic plants has been used less frequently: mostly limited to single and multiple indices, with some recent application to predictive modelling (Smith et al. 2009).

${ }^{\dagger}$ Deceased 26 November 2009 
Methods that use vegetation monitoring with a single metric or variable (such as abundance, species richness or diversity), or a single index (calculated using more than one metric), can be grouped into three categories: (1) community-based metrics, (2) metrics based on plant functional groups, and (3) species-specific metrics (USA EPA 2002). A community-based index can measure how the plant community responds to, for example, hydrological change, and impact can be detected by the changes in the ratio of native and exotic species. Changes to natural hydrological regimes (changes to water quality, water level and hydroperiod) have well documented impacts on plant communities (Reid \& Brookes 2000). Community-based metrics, such as species richness, can measure the response of the plant community to a disturbance: for example, the absence of species that are sensitive to the disturbance; the dominance of invasive and exotic species; or dominance of one species or one structural type will suggest a disturbance.

In the USA, a database has been established that lists the sensitivities of plant species and functional groups to different stressors (Adamus \& Gowyaw 2000). However, even this database only summarises data from $16 \%$ of water plant species (USA EPA 2002). The main difficulty facing the application of such an approach in Australia is the limited knowledge of water plant species responses to specific disturbances or impacts. While there is some recent literature on Australian water plant species and their response to specific disturbances (Blanch et al. 1999, Rea \& Storrs 1999, Blanch et al. 2000, Casanova \& Brock 2000, Rababah \& Ashbolt 2000, Robertson \& Rowling 2000, Morris \& Ganf 2001, Downes et al. 2002, Brock 2003, Reid \& Quinn 2004, Brock et al. 2005, Doupe et al. 2010, Mackay et al. 2010), further information remains in unpublished reports.

There are a number of indices that incorporate wetland vegetation (Table 1). The Hawkesbury-Nepean Wetland Assessment (HNWA) Index (Sainty \& Jacobs 1997) is an example of a local community-based index developed in Australia. This index relies on the assumption that impacted wetlands will contain more exotic species than less impacted wetlands, an assumption that was tested and found to be robust in the Hawkesbury-Nepean catchment (Sainty \& Jacobs 1997).

There are two potential sources of error in the calculation of an index: the collection of data and the analysis of the data. This paper aims to provide a sensitivity analysis of an established protocol (Hawkesbury-Nepean Wetland Assessment Index, Sainty \& Jacobs 1997) for the assessment of wetland condition across a range of wetland types and qualities over time.

\section{Methods}

Data were collected to test the sensitivity or vulnerability of a single index to data collection methods and to analytical techniques. These variables included sampling effort (number and size of quadrats), inclusion of dryland species and taxonomic resolution. Furthermore, a single index was used to test the importance of sampling design, pilot testing, as well as understanding the effects of errors when data are summarised into a single number/metric or index. By understanding the effects of errors on a single index, suppositions can be made to the orders of magnitude of the effects of errors for multiple metrics. 
Table 1. List of indices that use vegetation, the metrics used within each index, and references that use those indices.

Indices

Hawkesbury-Nepean Wetland Assessment (HNWA) Index

Index of Wetland

Condition (IWC)

The Sum Water Regime Index

Index of Stream

Condition (ISC)

Floristic Quality (FQAl) Assessment Index

\section{Metrics used}

Species richness and water quality indices

Dominance or cover class

Biomass

Number of exotic, native and noxious species

Metrics for soil, fringing and aquatic vegetation and water Australia quality

Depth and duration of inundation (an index of the hydrological past that plants had experienced)

Coefficient of conservatism, species richness and composition of native and exotic species Australia Australia Australia

\section{Study location}

Tasmania, Australia

New South Wales,

New South Wales,

New South Wales,

New South Wales,

South Australia

Victoria, Australia

Chicago USA

Ohio USA

Michigan USA

Illinois USA

Florida USA

Minnesota USA

Vascular plants; non-vascular

species; monocarpic species; aquatic guilds; sensitive taxa; tolerant taxa; dominance; persistent litter

Index for Biotic Integrity Total number of species, (IBI) for vascular plants number of sensitive species, number of tolerant species

USA

Great Lakes USA

North Dakota USA

DeKeyser et al. 2003

Adamus 1996

Mack 2001
Rea and Ganf 1994

\section{Reference}

Kirkpatrick and Harwood 1983

Gibson and Hurst 2005

Roberts et al. 2001

Sainty and Jacobs 1997

Spencer et al. 1998

Ladson et al. 1999

Wilhelm and Ladd 1988

Andreas and Lichvar 1995, Lopez and Fennessy 2002, Engle and Johansen 2002, Herman et al. 1996

Matthews 2003

Cohen et al. 2004

Gernes 2002

Gernes and Helgen 1999

Carlisle and Clements 1999

Albert and Minc 2004

Cohen et al. 2005
Species richness of native perennials, \% annuals and introduced species
Wetland Condition Index
Index of plant community Integrity (IPCI)

Herbaceous or Forested $\%$ non-native species, ratio
annual to perennial species, mean floristic quality score, $\%$ tolerant taxa, \% sensitive taxa, $\%$ native perennials, $\%$ wetland taxa 


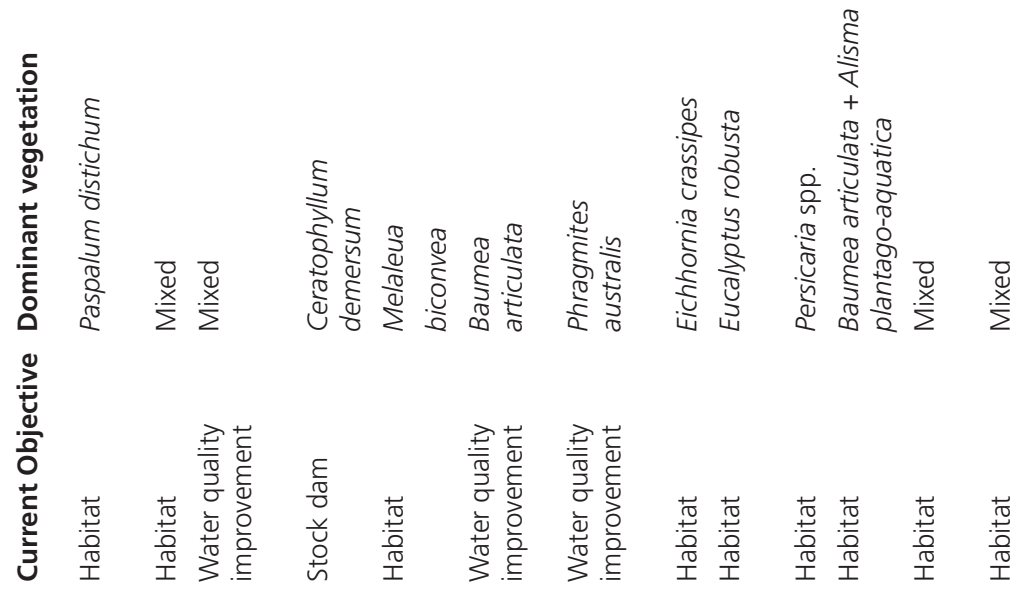

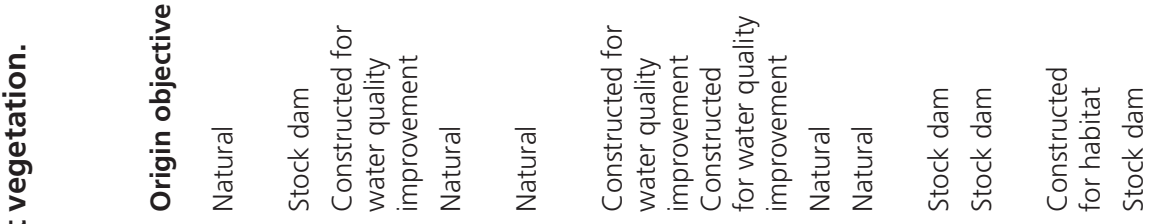

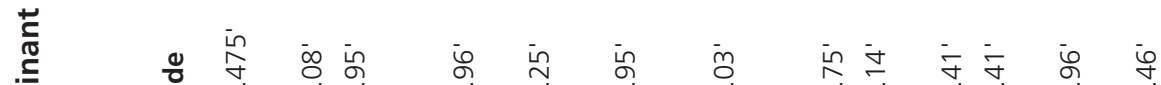

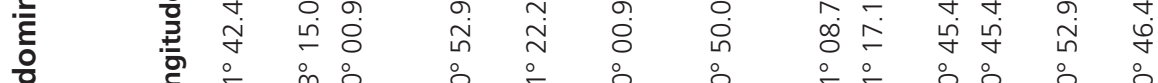

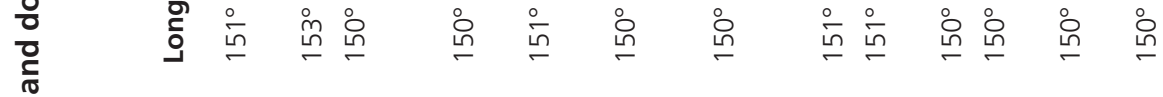

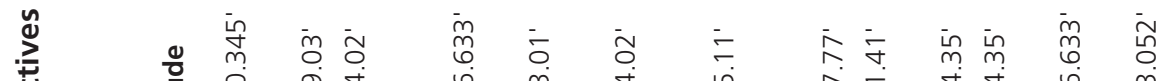

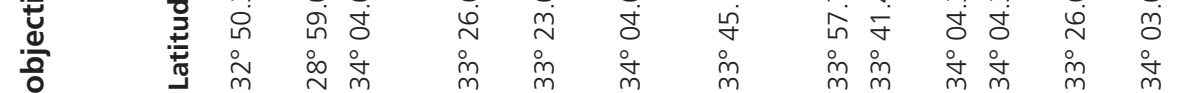

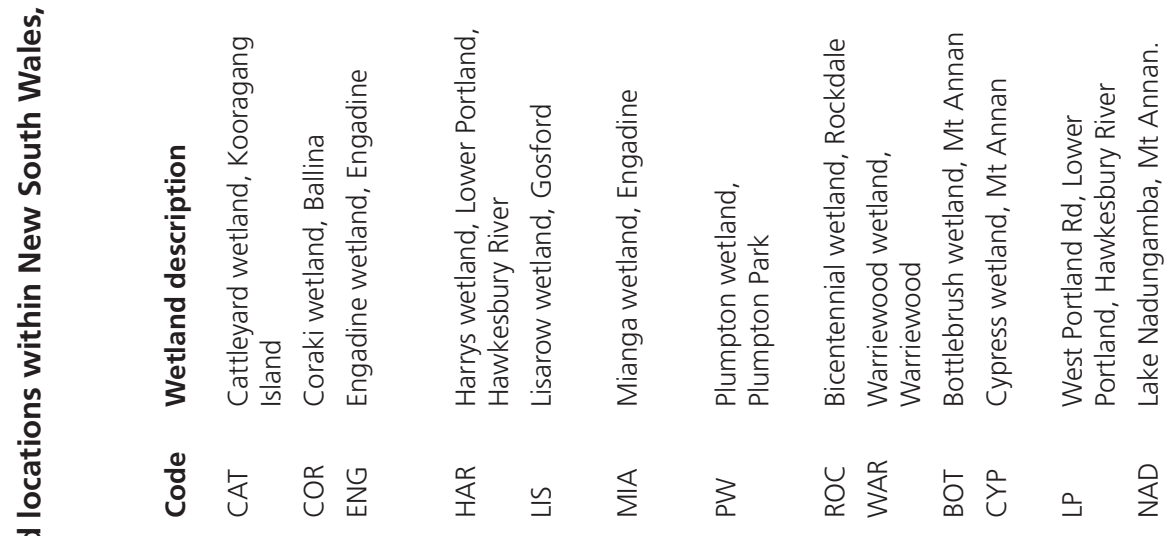




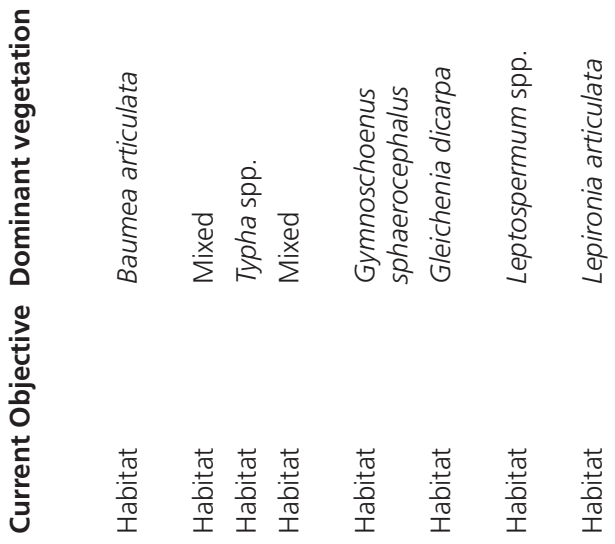

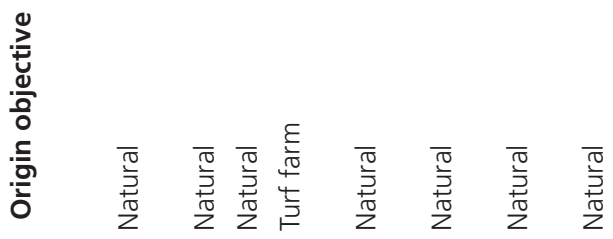

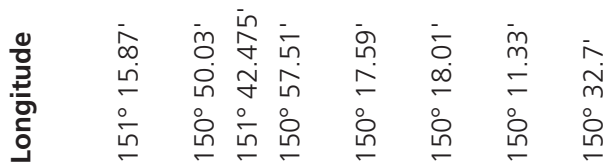

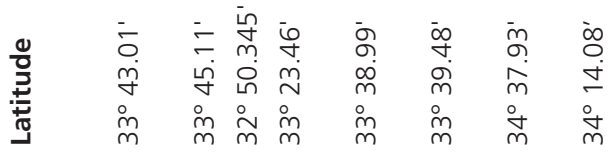

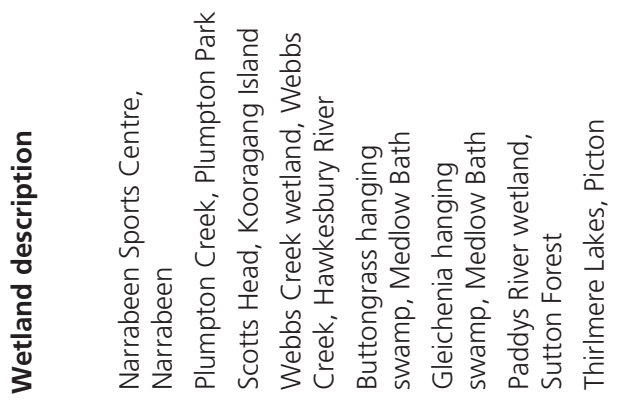

⿺辶巛

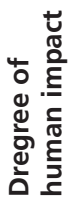


A broad definition of wetlands was used in this study to accommodate different types of wetlands in south-eastern Australia. Wetlands were defined as areas of land permanently or intermittently inundated with freshwater, or areas characterised by vegetation dependent on standing water for their maintenance.

A range of New South Wales wetlands were sampled (latitudes $34^{\circ} 37.93^{\prime}-32^{\circ} 50.345^{\prime}$ S; longitudes $153^{\circ} 15.08^{\prime}-150^{\circ} 00.95^{\prime} \mathrm{E}$ ) (Table 2). A total of 21 wetlands were sampled in autumn (April-May) and spring (August-October) of 2001-2003 (Table 2). Wetlands were selected to encompass a range of geomorphic settings, wetland types, function, size and dominant vegetation type (Table 2). These wetlands were categorised into: highly impacted (those constructed for water quality improvement or wetlands heavily impacted by human interference such as pollution or grazing); moderately impacted (wetlands with histories of anthropogenic-impacts but whose general objective, at the time of survey, was to provide wildlife habitat); and less impacted (located in conservation areas with little or no human disturbance locally or in their upper catchments).

An adaptation of the method of Gibson and Hurst (2005) for sampling aquatic vegetation was used for this study. We divided each wetland into compass sectors (north, south, east, west), and then each sector into different vegetation zones (emergent, submerged, floating or edge). A $100 \mathrm{~m}$ transect was placed across the contiguous vegetation zones (perpendicular to the water's edge). Twenty randomly placed $1 \mathrm{~m}^{2}$ quadrats were positioned along each transect, and the presence/absence and percentage cover of each species were recorded for each quadrat. Cover class was categorised as follows: 1, one individual; 2 , 1-10\% cover; $3,11-30 \%$ cover; $4,31-60 \%$ cover; $5,61-80 \%$ cover; 6 , $81-100 \%$ cover.

\section{The Hawkesbury-Nepean Wetland Assessment (HNWA) Index}

The HNWA Index (Sainty \& Jacobs 1997) scores the number of natives, introduced and noxious species (between 0 and 3 ) recorded at a site, according to estimates that greater than 17 native species in the Hawkesbury-Nepean region is considered good condition, and then sums the scores for an overall condition score for the site. A score of ' 9 ' indicates a wetland in excellent health with no introduced species present. The relevance of the index was increased by using the proportion of native and introduced species rather than a static constant (i.e., $>17$ is good condition) allowing the index to have a wider geographic application (Ling \& Jacobs 2003, Ling 2010). That is, a score of 3 was allocated to a site (or transect or quadrat) if the proportion of natives exceeded $80 \%$, and a score of 0 if the proportion of natives was less than $30 \%$ (Table 3 ). The scoring for the numbers of noxious species was left unchanged from the original protocol (Sainty \& Jacobs 1997), i.e., if the noxious or major weed species represented more than $11 \%$ the score was zero, between $1-10 \%$ scored 2 and none scored 3 (Table 3 ).

Table 3. Scores for the proportion of species richness and cover of native, introduced and noxious weeds, modified from Sainty and Jacobs (1997).

\begin{tabular}{lllll} 
& \multicolumn{5}{c}{ Scores for number of species and cover } \\
& 0 & 1 & 2 & 3 \\
$\%$ Native & $<30 \%$ & $31-60 \%$ & $61-80 \%$ & $81-100 \%$ \\
$\%$ Introduced species or minor weeds & $81-100 \%$ & $61-80 \%$ & $31-60 \%$ & $<30 \%$ \\
$\%$ Noxious species or major weeds & $>11 \%$ & & $1-10 \%$ & $0 \%$
\end{tabular}


A total score for a wetland of ' 9 ' was interpreted as indicating a wetland in "excellent" condition; '7' indicates a wetland with "some hope"; '5' indicates a wetland in "marginal" condition; '4 or less' indicates a wetland in "poor" condition (Sainty \& Jacobs 1997). This interpretation presupposes that the higher proportion of native species to exotic species indicates a wetland in better condition. This paper examines whether other variables challenge this supposition. Other variables tested for their effects on the index are data collection methods, and analytical considerations.

\section{Data collection methods}

Different methods of sampling vegetation will integrate considerations of plot location, shape, size and number. In Australia, the most extensive field surveys of wetland vegetation are limited to identifying dominant species and cover class of those dominants (Australian River Assessment Scheme, Anderson \& Raine 1995; Index of Stream Condition, Ladson et al. 1999; Index of Wetland Condition, DSE 2005; PressureBiota-Habitat, Chessman 2002).

Wetland vegetation surveys use a variety of quadrat sizes to estimate species present and cover class. Overseas, $1 \mathrm{~m}^{2}$ quadrats are often used for herbaceous plants (DeKeyser et al. 2003, U.S E.P.A. 2002, Magee \& Kentula 2005), while $10 \times 10 \mathrm{~m}$ plots are commonly used for forested wetlands (Austin \& Greig-Smith 1968). Some surveys vary the shape of the plot by using $0.5 \times 2 \mathrm{~m}$ plots for aquatic vegetation and $0.5 \times 4 \mathrm{~m}$ plots for woody species (Auble et al. 2005) or circular plots (Fortney et al. 2003). In Australia, submerged aquatic vegetation surveys that test for biomass have used $0.04 \mathrm{~m}^{2}$ quadrats (Roberts et al. 1999, 2001; Royle \& King 1991; AMBS 2000) while others that measure cover class and species richness use $1 \mathrm{~m}^{2}$ quadrats (Jacobs et al. 1994, Gibson \& Hurst 2005). No Australian studies could be found on testing sampling effort of vegetation surveys appropriate for Australian rivers or wetlands. The influence of sampling effort was tested by collecting data from two different quadrat sizes: $1 \mathrm{~m}^{2}$ and $0.0625 \mathrm{~m}^{2}$ $(0.25 \times 0.25 \mathrm{~m})$.

\section{Analytical considerations}

Different analytical considerations are also hypothesized to affect the accuracy and precision of an index, including whether one records all species or only aquatic species, taxonomic resolution, inclusion of rare species, sampling effort, spatial and temporal variability, performance, cover class and scaling of the index.

While classification of species as strictly aquatic or not is subjective, it has been argued that there is a need to identify all species rather than just the obligate aquatic species. Dryland species were defined as those tolerant of flooding but not exhibiting a dependence on flooding for part of their life cycle. Wetland species were defined as those that require some inundation to complete their life cycle (Sainty \& Jacobs 1981, 2003; Jacobs 1983, 2005). Data were analysed to evaluate the influence on the index of either including all species or only the aquatic species.

To explore the influence of taxonomic resolution on the index, all taxa were identified to species so that comparisons could be made between specific, generic, and familial resolution of identification. 
- DAUATICS only DALL species recorded

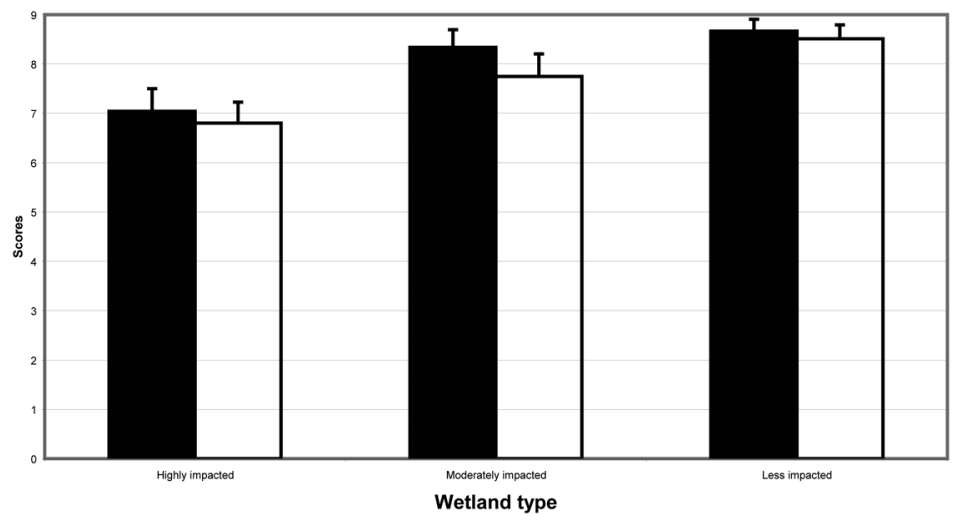

Fig. 1. Average Hawkesbury-Nepean Wetland Assessment (HNWA) Index (mean and SE) (scored by proportions) comparing all species recorded and only aquatic species data.

Code to interpret the HNWA Index (Sainty \& Jacobs 1997): <4, poor; 5, marginal; 7, hope; 9 excellent.

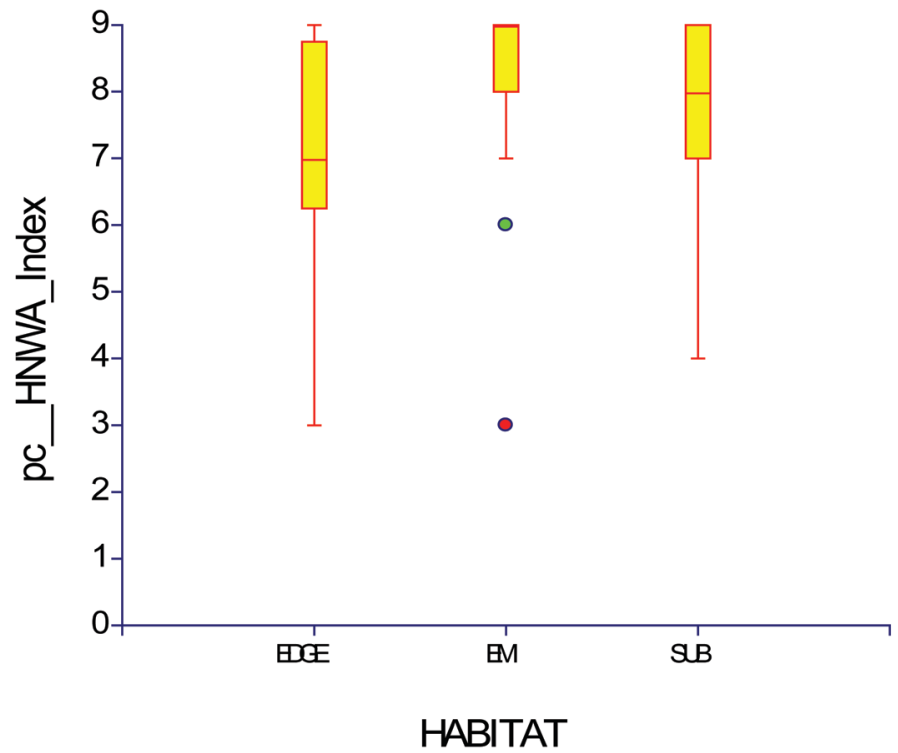

Fig. 2. Boxplots for Hawkesbury-Nepean Wetland Assessment (HNWA) Index scores in the three different vegetation zones: edge, emergent (EM) and submerged (SUB). One-way ANOVA indicates that there is a significant difference between habitats at $\alpha=0.05$. 
To explore whether the underestimation of native or introduced species changed the index, all taxa were identified and categorised as native or exotic.

Spatial and temporal variation scores were analysed using a three-way nested ANOVA with 'season' as the first factor (fixed), 'degree of human impact' as the second factor (random) and 'sites' (nested in degree of human impact) as the third factor (NCSS statistical package).

The HNWA protocol is based on an overall assessment of a wetland and does not use quadrats to represent the wetland plants. Therefore, the use of quadrat data is to explore the effects of errors using real data rather than subjective estimates (of native and introduced species numbers and cover of an entire wetland) as is used in the original HNWA protocol. To evaluate the performance or frequency of the score for each quadrat within a transect (i.e., how many quadrats within a transect had the same score), a score for the cumulative 20 quadrats was calculated for all transects sampled in autumn 2001.

Other metrics were also calculated that could potentially improve the sensitivity of the index. These included: cover class (total cover of native, introduced and noxious weeds calculated as a proportion of the total cover) (Table 3); cover class and counts (average between the percent cover and the number of species); and scaling of the scores (each score was converted to a proportion of the highest score).

\section{Results}

\section{Data collection methods}

Calculating the scores for the two quadrat sizes, found that the smaller quadrat $(0.25 \mathrm{~m}$ $\times 0.25 \mathrm{~m}$ ) underestimated both native and introduced species compared to the $1 \mathrm{~m}^{2}$ quadrat (Table 4).

Over half of the species recorded were categorised as dryland species and results showed that for most wetlands, there was little change to the HNWA scores when the 'dryland' species were excluded (Fig. 1). Only scores for two sites (Lower Portland and Lake Nadungamba) indicated worse wetland condition with inclusion of dryland species $(>7,<7$, respectively), a consequence of the majority of dryland species also being categorised as introduced.

Significant differences in the scores were identified between 'sites' nested in degree of human impact $(\mathrm{p}<0.0001$, Table 5$)$. Other factors were not significant, suggesting that variation within and between 'sites' is more significant than any overall differences between 'seasons' or putative 'degree of human impact' (Table 5).

To explore the differences between scores across vegetation zones within a wetland, overall wetland scores were compared to scores for each zone (i.e., edge, emergent, floating, submerged) (Fig. 3). For most sites, the scores for each vegetation zone did not change the final assessment of the wetland. However, when the scores varied over a critical interpretation value, such as ' 7 ', then there is the potential for misinterpretation when only one vegetation zone is assessed. For example, at Mianga wetland, the score for the edge habitat was considerably lower (6.5) than the emergent zone (8.25) (Fig. 3). When each of the transects were analysed separately, the 'edge' vegetation zone had significantly lower scores than the other vegetation zones ( $\mathrm{p}<0.05$, Fig. 2$)$, but this was again site dependent. 
Table 4. Hawkesbury-Nepean Wetland Assessment (HNWA) Index scores for wetland sites using a (a) $0.0625 \mathrm{~m}^{2}$ or (b) $1 \mathrm{~m}^{2}$ quadrat.

\begin{tabular}{|c|c|c|c|c|c|c|c|}
\hline $\begin{array}{l}\text { Wetland } \\
\text { Site }\end{array}$ & $\begin{array}{l}\text { Quadrat } \\
\text { size }\end{array}$ & $\begin{array}{l}\text { No. } \\
\text { Introduced }\end{array}$ & $\begin{array}{l}\text { No. } \\
\text { Native }\end{array}$ & $\begin{array}{l}\text { No. } \\
\text { Noxious }\end{array}$ & $\begin{array}{l}\text { No. } \\
\text { species }\end{array}$ & Score & $\begin{array}{l}\% \mathrm{H}-\mathrm{N} \\
\text { Index }\end{array}$ \\
\hline \multirow[t]{2}{*}{ CYP } & 0.0625 & 2 & 10 & 0 & 12 & 7 & EXCELLENT \\
\hline & 1 & 2 & 11 & 0 & 13 & 9 & EXCELLENT \\
\hline \multirow[t]{2}{*}{ LP } & 0.0625 & 7 & 23 & 0 & 30 & 8 & EXCELLENT \\
\hline & 1 & 11 & 27 & 0 & 44 & 7 & EXCELLENT \\
\hline \multirow[t]{2}{*}{ MIA } & 0.0625 & 4 & 10 & 0 & 14 & 8 & EXCELLENT \\
\hline & 1 & 9 & 11 & 0 & 20 & 6 & SOME HOPE** \\
\hline \multirow[t]{2}{*}{ NAD } & 0.0625 & 6 & 12 & 0 & 18 & 7 & SOME HOPE \\
\hline & 1 & 7 & 13 & 0 & 25 & 7 & SOME HOPE \\
\hline \multirow[t]{2}{*}{ PC } & 0.0625 & 1 & 11 & 0 & 12 & 8 & EXCELLENT \\
\hline & 1 & 2 & 13 & 0 & 14 & 8 & EXCELLENT \\
\hline \multirow[t]{2}{*}{ PW } & 0.0625 & 1 & 5 & 0 & 6 & 6 & EXCELLENT \\
\hline & 1 & 2 & 5 & 0 & 7 & 6 & EXCELLENT \\
\hline \multirow[t]{2}{*}{ TH } & 0.0625 & 1 & 6 & 0 & 6 & 6 & EXCELLENT \\
\hline & 1 & 1 & 7 & 0 & 7 & 7 & EXCELLENT \\
\hline
\end{tabular}

**, scores where the larger quadrat results in a change in the assessment. Code to interpret the HNWA Index (Sainty and Jacobs 1997): <4, poor; 5, marginal; 7, hope; 9 excellent.

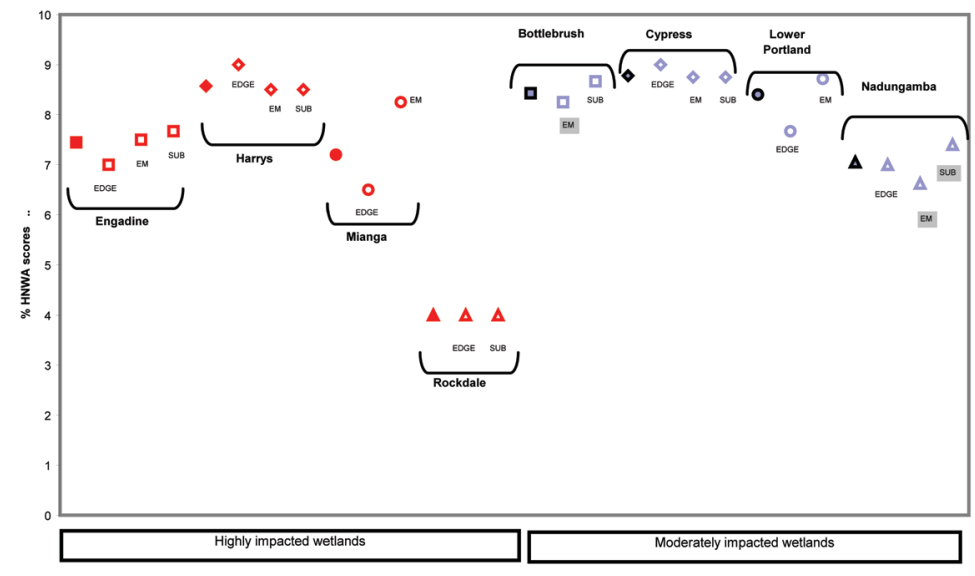

Fig. 3. Hawkesbury-Nepean Wetland Assessment (HNWA) Index scores for wetlands with different vegetation zones or microhabitats: edge, emergent (EM) and submerged (SUB).

Solid shapes indicate the HNWA score when all zones are averaged, hollow shapes indicate the HNWA scores for the average of each zone calculated separately. Code to interpret the HNWA scores (Sainty \& Jacobs 1997): <4, poor; 5, marginal; 7, hope; 9 excellent. 


\section{Analytical considerations}

Scores for the cumulative species for 15 to 20 quadrats were calculated for all transects sampled in autumn 2001 (Table 6). Even though all species were not always represented in the 15 quadrats, most of the scores calculated from the 15 were the same as the score for 20 quadrats. There was only one occasion (Lower Portland wetland) when the score was lower for the 15 quadrats (score of 7 ) than for the 20 quadrats (score of 8 ).

Wetlands that are $100 \%$ native species (natural wetlands) or $100 \%$ introduced, there is no difference in the scores using either proportion or counts of native or introduced species. However, those wetlands with more cover of introduced or noxious species resulted in lower scores (more degraded assessment) despite having a higher proportion of native species compared to introduced species. Conversely, wetlands with more cover of native species had higher scores despite having lower numbers of native species compared to introduced species. This relationship between the number of native and introduced species was confirmed with a linear regression that the proportion of native species was positively related to the percent cover of native species $(p=0.72)$ with more than half the variation in numbers accounted for by variation in the cover of native species $\left(r^{2}=0.5136\right)$. There was a similar result for the proportion and the cover of introduced species $\left(\mathrm{p}=0.70, \mathrm{r}^{2}=0.4938\right)$. The index using both cover class and the number of species was an average of the two indices based on individual variables (Fig. 4).

Scaling, or comparing each score with the maximum score over time or location or dataset, enables comparisons to be relative rather than to an artificial optimum condition. Scaling the scores over each wetland resulted in little effect on the overall scoring of the wetlands when averaged across wetland impact since many of the wetlands had the maximum score (9) and so scaling had little effect to the overall scoring of the wetlands (Fig. 5).

\section{Discussion}

\section{Data collection methods}

The HNWA Index is based on an overall assessment of a wetland and does not necessarily use quadrats to sample wetland plants. The assessment of the HNWA Index using field survey data was simply to illustrate the effects of under- or overestimation of species richness. The comparison of species numbers estimated from data obtained from $1 \mathrm{~m}^{2}$ compared to $0.065 \mathrm{~m}^{2}$ quadrats demonstrated that species number could be underestimated by smaller quadrat sizes. Four possible scenarios were identified: underestimation of (a) native species, (b) introduced species, (c) both the native and introduced species, and (d) both remain the same.

Underestimation of native species increases the probability of 'measuring' an impact when there is none, also known as Type I error. Underestimation of introduced species also changed the abundance grouping and consequently altered a wetland's score. For example, in the case of the Mianga wetland, the smaller quadrat recorded four $(28 \%)$ introduced species, putting it into the abundance class of $<30 \%$ exotic species, giving it a score of ' 3 '. On the other hand, the larger quadrat picked up more introduced species ( 9 species or $45 \%$ ) thereby generating a lower score of ' 2 '. Also the smaller quadrat recorded 10 native species ( $71 \%$ ), thereby scoring a '2', whereas the 11 native species in 


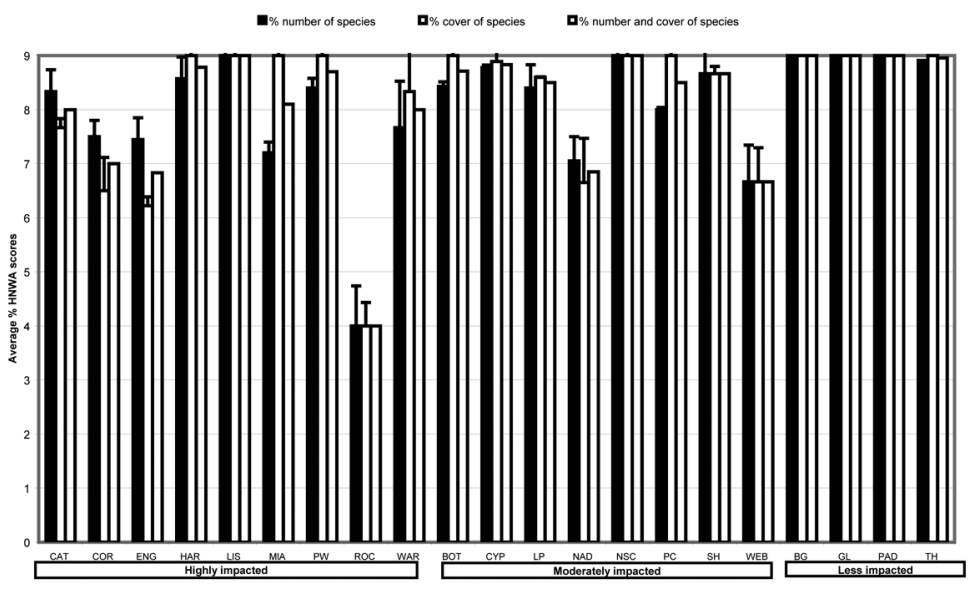

Fig. 4. Average Hawkesbury-Nepean Wetland Assessment (HNWA) Index scores (mean and SE) (scored by percent) comparing the species richness, cover and the sum of the richness and cover of species.

Code to interpret the HNWA Index (Sainty \& Jacobs 1997): <4, poor; 5, marginal; 7, hope; 9 excellent.

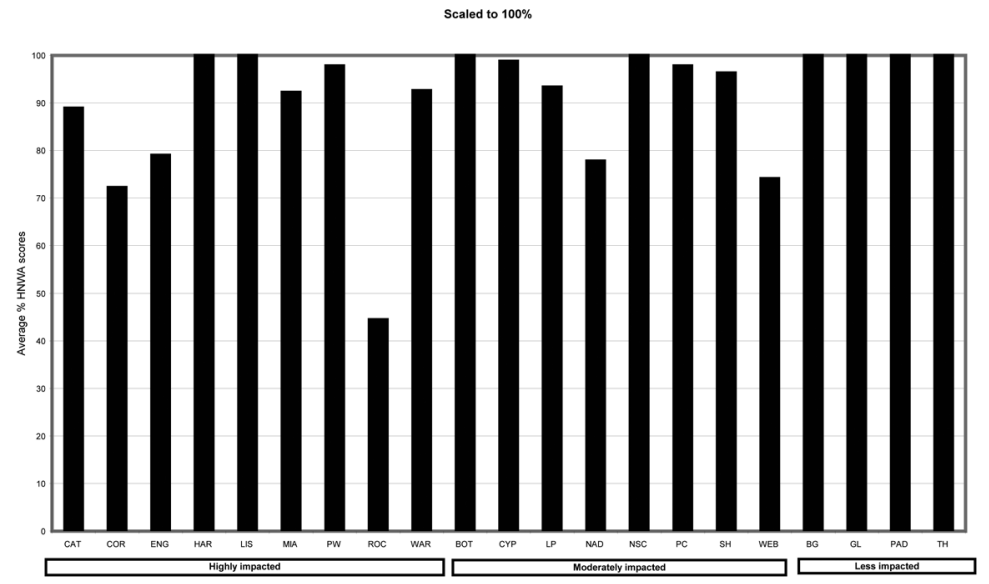

Fig. 5. Average Hawkesbury-Nepean Wetland Assessment (HNWA) Index scores for each site scaled to $100 \%$ showing little effect of scaling due to many of the wetlands having optimal scores of 9 (see text for explanation). 
the larger quadrat (only 55\%) represented a score of ' 1 '. Neither quadrat recorded any noxious species, thereby giving total scores for the smaller quadrat as ' 8 ' and "excellent", and the larger quadrat as ' 6 ' and in the "some hope" category. This underestimation of the introduced species in the smaller quadrat increases the probability of not detecting an impact when there is an impact, or a Type II error.

When both native and introduced species are underestimated by using too small a quadrat, the scores cancelled each other out. Percentages of both the native and introduced species remained in the same abundance class, causing no change to the calculation of the scores and the assessments remain the same (Cypress, Lower Portland, Plumpton Creek and Thirlmere Lakes wetlands).

Therefore, quadrat size can influence the final assessment of a wetland and the selection of quadrat size should be based on pilot studies testing quadrat size with considerations of wetland type. Ultimately, whatever quadrat size is selected, it should be sufficiently large to provide consistent measures across all wetlands compared. This is also the case for selection and analysis of vegetation zones, since the compositional proportions of the vegetation zone will differ and this can also impact the score.

In addition, underestimation of the number of native or introduced species in a wetland can also be introduced by misidentification of species. Misidentification is especially difficult to detect, and is rarely discussed in the literature (Scott \& Hallam 2002) but is clearly a source of error that may affect vegetation indices. This highlights the importance of collecting reference specimens that are retained for later reinterpretation, identification and analysis.

Performance, or frequency of the same score, was high for 15 to 20 quadrats, indicating that 20 quadrats in a transect provides good precision (or estimate) of the scores within a vegetation zone. The only exception to this was due to the underestimation of native species resulting in an increase in the probability of detecting an impact when there is none (Type I error).

Table 5. Three-factor analysis of variance (ANOVA) results for species richness and cover class.

$\begin{array}{llrlll}\text { Source of variation } & \text { Type } & \text { df } & \text { SS } & \text { F } & \text { p } \\ \text { A: degree of human impact } & \text { Fixed } & 2 & 19.23804 & & \\ \text { B(A): Site } & \text { Nested } & 14 & 73.22357 & 9.74 & 0.000001 \text { * } \\ \text { C: Season } & \text { Random } & 3 & 0.8127926 & 0.50 & 0.682907 \\ \text { AC } & & 6 & 3.846385 & 1.19 & 0.343238 \\ \text { BC(A) } & & 24 & 12.89181 & 0.72 & 0.802553 \\ \text { S } & 44 & 32.75 & & \\ \text { Total (Adjusted) } & & 93 & 143.617 & & \end{array}$

* denotes term significant at $\alpha=0.05$ 
Even though over half of the species were identified in this study as dryland species, there was little change to the assessment of most wetlands when the non-aquatic species were excluded from the analyses. For two of the wetlands, the scores suggested that the condition of the wetland was worse than when dryland species were included. This was a result of the high proportion of introduced species among the dryland species.

\section{Analytical considerations}

If the flora of an area is reasonably well known, then accurate results can be expected if vouchers are collected and are authenticated. As proposed in the sections using different quadrat sizes, misidentifications can result in an incorrect estimation of the wetland scores.

Wetlands include several families which have both native and introduced taxa and multivariate analysis of taxa only identified to the family-level provide little information for delineating natural (less-impacted) and impacted wetland sites, compared to genus-level analyses (Ling 2010). However, some genera still contain both native and weedy species (e.g., Alternanthera philoxeroides and A. denticulata; Paspalum distichum and P. dilatatum; Cyperus difformis and C. eragrostis). We suggest that if higher level aggregation is required, identification and classification of native, exotic or noxious species will still need to be done at species level for selected families, rather than a total aggregation to family or genus-level.

Table 6. Hawkesbury-Nepean Wetland Assessment (HNWA) Index scores calculated for each quadrat in transects for sites sampled in autumn 2001.

* indicates a score different to the score for 20 quadrats. Code to interpret the HNWA scores (Sainty \& Jacobs 1997): <4, poor; 5, marginal; 7, hope; 9 excellent.

Average of 15-20 quadrats

\begin{tabular}{|c|c|c|c|c|c|c|}
\hline Site & Habitat & 15 & 16 & 17 & 18 & 19 \\
\hline \multirow[t]{2}{*}{ Mianga Wetland } & Edge & 6 & 6 & 6 & 6 & 6 \\
\hline & Emergent & 6 & 6 & 6 & 6 & 6 \\
\hline Plumpton Wetland & Emergent & 8 & 8 & 8 & 8 & 8 \\
\hline \multirow[t]{2}{*}{ Cypress Wetland } & Edge & 9 & 9 & 9 & 9 & 9 \\
\hline & Submerged & 9 & 9 & 9 & 9 & 9 \\
\hline \multirow[t]{3}{*}{ Lower Portland Wetland } & Emergent & 8 & 8 & 8 & 8 & 8 \\
\hline & Emergent & 9 & 9 & 9 & 9 & 9 \\
\hline & Emergent & $7 *$ & 8 & 8 & 8 & 8 \\
\hline \multirow[t]{4}{*}{ Lake Nadungamba } & Edge & 7 & 7 & 7 & 7 & 7 \\
\hline & Submerged & 8 & 8 & 8 & 8 & 8 \\
\hline & Edge & 6 & 6 & 6 & 6 & 6 \\
\hline & Submerged & 8 & 8 & 8 & 9 & 9 \\
\hline Plumpton Creek & Emergent & 9 & 9 & 9 & 9 & 9 \\
\hline \multirow[t]{2}{*}{ Thirlmere Lakes } & Emergent & 9 & 9 & 9 & 9 & 9 \\
\hline & $\begin{array}{l}\text { Emergent } \\
\text { Emergent }\end{array}$ & $\begin{array}{l}9 \\
8\end{array}$ & $\begin{array}{l}9 \\
8\end{array}$ & $\begin{array}{l}9 \\
8\end{array}$ & $\begin{array}{l}9 \\
8\end{array}$ & $\begin{array}{l}9 \\
8\end{array}$ \\
\hline
\end{tabular}


Initial testing of the HNWA Index (Ling \& Jacobs 2003) in seven natural and habitat wetlands over one season, found that proportions rather than numbers of native and introduced species gave the index a wider application to wetlands outside the Hawkesbury-Nepean catchment. This study using 21 wetlands over a two year period has supported this conclusion. However, inclusion of highly degraded wetlands has also highlighted the need to include cover as a measure in the index. This was evident in the scores of the degraded wetland at Coraki. The submerged habitat of Coraki wetland was visually dominated by the free-floating noxious weed, water hyacinth (Eichhornia crassipes). The importance of that species on the health of the wetland was not reflected in the index since the presence of only one noxious species represented less than $5 \%$ of the total number of species, whilst covering over $80 \%$ of the wetland.

Scaling the scores (converting each score to a percentage of the highest score) allows the scores to be compared relative to one another (spatially and temporally) and enables the use of reference sites to be incorporated. While scaling the HNWA scores results cannot be interpreted in the sense that $>7$ is a pristine wetland or a score of $<4$ is an impacted wetland, as originally prescribed by the developers (Sainty \& Jacobs 1997), it does provide the potential to compare scores with well chosen reference sites and enable the data to be analysed using analysis of variance techniques. Selection of the sites in this project was not to test for particular impacts of any particular wetland type. That is, the natural wetlands were not sampled as reference sites for the impacted wetlands, but rather as wetlands with little or no human disturbance. However, scaling the scores would be appropriate for surveys within a local government area that incorporated similar wetland types of different qualities. It would allow managers or stewards of wetlands to develop a baseline index specifically for the wetland vegetation in a region and enable the prioritisation of wetlands.

When the restoration of impacted wetlands is being considered, we suggest that an appropriate 'un-impacted' natural wetland be used as a baseline for prioritising which wetlands to restore. The HNWA Index scores of this natural wetland could be used as indicators of how the restoration is proceeding.

\section{Conclusions}

The results of our study in southeast Australia demonstrate that sampling effort and the variables chosen influence wetland health indices in the Hawkesbury-Nepean Wetland Assessment (HNWA) index. We demonstrated that the proportion of species, rather than numbers of native and exotic species, should be used to allow the index a wider geographic application to wetlands outside the Hawkesbury-Nepean region (Ling \& Jacobs 2003, Ling 2010).

The vegetation-based wetland index of Sainty and Jacobs (1997) has been here modified to incorporate percent plant cover, with a recommendation to scale the scores (compare to maximum scores). The modified index is simpler and has a wider geographic application than the other Australian options available, as it is not specific to wetland type, or regionally based.

The application of data from this study highlighted the effects of errors that can be made in summarising data into a single index and the need for careful consideration of aggregation of taxonomic information, sampling effort (quadrat number and size), 
sampling designs including reference sites. Consideration of the number and size of quadrats and habitat type are necessary to minimise the effects of errors, as well as considerations of quality control and assurance issues.

Information is lost in any index since only measures of number (or proportion) of native, introduced and noxious species are used. Other measures such as cover class, abundance, sensitivity or tolerance of a species to natural disturbances such as hydrological change (e.g. drought, flood, salinity), species characteristics (e.g. successional, perennial, annual, or opportunistic species) and human-induced disturbances (siltation, litter, cattle, stormwater pollution) may also provide valuable information for the assessment of a wetland.

\section{Acknowledgments}

This study was funded by the Australian Research Council as part of a PhD project (JL). The authors thank the following field volunteers: J. Ellen, J. Martin, P. Laegdsgaard and J. Green. Thanks to Department of Environment Climate Change and Water (DECCW) colleagues, particularly K. Rogers, for their support and encouragement.

JL would like to thank and honour Surrey Jacobs for his constant belief and enthusiasm in the natural world, people and robust science.

\section{References}

Adamus PR (1996) Bioindicators for Assessing Ecological Integrity of Prairie Wetlands. United States Environmental Protection Agency, National Health and Environmental Effects Research Laboratory, Western Ecology Division, Corvallis, OR.

Adamus P \& Gonyaw A (2000) National database of wetland plant tolerances. Prepared for the USA Environment Protection Agency. (http://www.epa.gov/owow/wetlands/bawwg/ publicat.html) (Downloaded June 2001)

Albert DA \& Minc LD (2004) Plants as regional indicators of Great Lakes coastal wetland health. Aquatic Ecosystem Health and Management 7: 233-247.

Anderson JR \& Raine AW (1995) Value and condition of riparian and instream habitats adjoining public lands in the upper North East Region of New South Wales. Technical Services Division of the Department of Land and Water Conservation.

Andreas BK \& Lichvar RW (1995) Floristic index for establishing assessment standards: a case study for northern Ohio. Technical Report WRP-DE-8, US Army Corps of Engineers.

Auble GT, Scott ML \& Freidman JM (2005) Use of individualistic streamflow - vegetation relations along the Fremont River, Utah, USA to assess impacts of flow alteration on wetland and riparian areas. Wetlands 25: 143-154.

Austin MP \& Greig-Smith P (1968) The application of quantitative methods to vegetation survey. II. Some methodological problems of data from rainforests. Journal of Ecology 56: 827-844.

Australian Museum Business Services: AMBS (2000) Australian Museum Business Services Final Report: Experimental Environmental Flow Strategy. Sydney Catchment Authority Contract 14849.

Blanch SJ, Ganf GG \& Walker KF (1999) Tolerance of riverine plants to flooding and exposure indicated by water regime. Regulated Rivers: Research and Management 15: 43-62.

Blanch SJ, Walker KF \& Ganf GG (2000) Water regimes and littoral plants in four weir pools of the River Murray, Australia. Regulated Rivers: Research and Management 16: 445-456. 
Brock MA (2003) Australian wetland plants and wetlands in the landscape: Conservation of diversity and future management. Aquatic Ecosystem Health and Management 6: 29-40.

Brock MA, Nielsen DL \& Crossle K (2005) Changes in biotic communities developing from freshwater wetland sediments under experimental salinity and water regimes. Freshwater Biology 50: 1376-1390.

Carlisle DM \& Clements WH (1999) Sensitivity and variability of metrics used in biological assessments of running waters. Environmental Toxicology and Chemistry 18: 285-291.

Casanova MT \& Brock MA (2000) How do depth, duration and frequency of flooding influence the establishment of wetland plant communities? Plant Ecology 147: 237-250

Chessman BC (2002) Assessing the conservation value and health of New South Wales rivers: The PBH (Pressure-Biota-Habitat) Project. Centre for Natural Resources, NSW Department of Land and Water Conservation, Parramatta

Cohen MJ, Carstenn S \& Lane CR (2004) Floristic quality indices for biotic assessment of depressional marsh condition in Florida. Ecological Applications 14: 784-794.

Cohen MJ, Lane CR, Reiss KT, Surdick JA, Bardi E \& Brown MT (2005) Vegetation based classification trees for rapid assessment of isolated wetland condition. Ecological Indicators 5: 189-206.

DeKeyser ES, Kirby DR \& Ell MJ (2003) An index of plant community integrity: development of the methodology for assessing prairie wetland plant communities. Ecological Indicators 3: 119-133.

Department of Sustainability and Environment (2005) Index of Wetland Condition: Conceptual framework and selection of measures. (Victorian Government Department of Sustainability and Environment: Melbourne)

Doupe, RG.; Mitchell, J.; Knott, M.J; Davis, AM.; Lymbery \& AJ. (2010) Efficacy of exclusion fencing to protect ephemeral floodplain lagoon habitats from feral pigs (Sus scrofa). Wetlands Ecology and Management 18 (1): 69-78.

Downes BJ, Barmuta LA, Fairweather PG, Faith DP, Keough MJ, Lake PS, Mapstone BD \& Quinn GP (2002) Monitoring Ecological Impacts: Concepts and Practice in Flowing Waters. (Cambridge University Press: Melbourne)

Engle TL \& Johansen JR (2002) Does a correlation between the floristic quality index and coefficients of wetness exist. Ohio Journal of Science 102 (1): 11.

Fortney RH, Benedict M, Gottgens JF, Walters TLL \& Rentch J (2003) Aquatic plant community composition and distribution along and inundation gradient at two ecologically distinct sites in the Pantanal region of Brazil. Wetlands Ecology and Management 12: 575-585

Gernes M (2002) Appendix C: Minnesota Index of Vegetative Integrity (IVI). In: Methods for evaluating wetland condition. Using vegetation to assess environmental condition in wetlands. USEPA Office of Water: Washington (ed.), D.C. EPA-822-R-02-020.

Gernes MC \& Helgen JC (1999) Indexes of biotic integrity (IBI) for wetlands: vegetation and invertebrate IBIs. Final report to the US Environmental Protection Agency CD995525.01. Minnesota Pollution Control Agency, St. Paul, Minnesota, USA.

Gibson M \& Hurst C (2005) Snowy River flow response monitoring project: changes in vegetation communities after the first flow release to the Snowy River downstream of Jindabyne Dam. Report prepared for the Department of Infrastructure, Planning and Natural Resources New South Wales.

Herman K, Masters LA, Penskar MR, Reznicek AA, Wilhelm GS \& Brodowicz WW (1996) Floristic quality assessment for Michigan. Great Lakes Wetlands 7 (4): 1-5.

Jacobs SWL (1983) Wetlands Vegetation. Pp. 14-19 in Haigh C (ed.) Parks and Wildlife, Wetlands Issue. (National Parks and Wildlife Service: Sydney)

Jacobs SWL (2005) Identifying Waterplants. In: Identification and assessment of aquatic macrophytes: Wetland Education and Training (WET. Program, 10-11 November 2005. Sydney Olympic Park) 
Jacobs SWL, Perrett F, Sainty GR, Bowmer KH \& Jacobs BJ (1994) Ludwigia peruviana (Onagraceae) in the Botany wetlands near Sydney, Australia. Australian Journal of Marine and Freshwater Research 45: 1481-1490.

Kirkpatrick JB \& Harwood CE (1983) Plant communities of Tasmanian wetlands. Australian Journal of Botany 31: 437-451.

Ladson AR, White LJ, Doolan JA, Finlayson BL, Hart BT, Lake PS \& Tilleard JW (1999) Development and testing of an Index of Stream Condition for waterway management in Australia. Freshwater Biology 41: 453-468.

Ling JE (2010) Testing aquatic macroinvertebrate and plant techniques for the biological assessment of wetlands: a consideration of the effects of errors and implications for sampling design. (VDM Publishing Verlag Dr. Müller e.K)

Ling JE \& Jacobs SWL (2003) Biological assessment of wetlands: testing techniques - preliminary results. Wetlands (Australia) 21: 36-55.

Lopez RD \& Fennessy MS (2002) Testing the floristic quality assessment index as an indicator of wetland condition. Ecological Applications 12: 487-497.

Mack J (2001) Vegetation index of biotic integrity (VIBI. for wetlands: Ecoregional, hydrogeomorphic and plant community comparisons with preliminary wetland aquatic life use designations. Final report to the US EPA Grant No. CD985276 Interim report to US EPA Grant No. CD 985875-01 Testing biological metrics and development of wetland assessment techniques using reference sites. Volume 1.

Mackay SJ, James, CS \& Arthington AH (2010) Macrophytes as indicators of stream condition in the wet tropics region, Northern Queensland, Australia. Ecological Indicators 10: 330-340.

Magee TK \& Kentula ME (2005) Response of wetland plant species to hydrologic conditions. Wetlands Ecology and Management 13: 163-181.

Matthews JW (2003) Assessment of the floristic quality index for use in Illinois, USA, Wetlands. Natural Areas Journal 23: 53-60.

Morris K \& Ganf GG (2001) The response of an emergent sedge Bolboschoenus medianus to salinity and nutrients. Aquatic Botany 70: 311-328.

Rababah AA \& Ashbolt NJ 2000. Innovative production treatment hydroponic farm for primary municipal sewage utilisation. Water Research 34: 825-834.

Rea N and Ganf GG (1994) How emergent plants experience water regime in a Mediterraneantype wetland. Aquatic Botany 49: 117-136.

Rea N \& Storrs MJ (1999) Weed invasions in wetlands of Australia's Top End: reasons and solutions. Wetlands Ecology and Management 7: 47-62.

Reid MA \& Brooks JJ (2000) Detecting effects of environmental water allocations in wetlands of the Murray-Darling Basin, Australia. Regulated Rivers: Research \& Management 16: 479-496.

Reid MA \& Quinn GP (2004) Hydrologic regime and macrophyte assemblages in temporary floodplain wetlands: implications for detecting responses to environmental water allocations. Wetlands 24: 586-599.

Roberts DE, Church AG \& Cummins SP (1999) Invasion of Egeria into the Hawkesbury-Nepean River, Australia. Journal of Aquatic Plant Management. 37: 31-34.

Roberts DE, Sainty GR, Cummins SP, Hunter GJ \& Anderson LWJ (2001) Managing submersed aquatic plants in the Sydney International Regatta Centre, Australia. Journal of Aquatic Plant Management 39: 12-17.

Robertson AI \& Rowling RW (2000) Effects of livestock on riparian zone vegetation in an Australian dryland river. Regulated Rivers: Research \& Management 16: 527-541.

Royle RN \& King RJ (1991) Aquatic macrophytes in Lake Liddell, New South Wales: biomass, nitrogen and phosphorus status, and changing distribution from 1981 to 1987. Aquatic Botany 41: 281-298.

Sainty GR \& Jacobs SWL (1981) Waterplants of New South Wales. Water Resources Commission NSW.

Sainty GR \& Jacobs SWL (1997) Hawkesbury-Nepean wetland assessment. Prepared for the Hawkesbury-Nepean Catchment Management Trust. 19 pages. 
Sainty GR \& Jacobs SWL (2003) Waterplants in Australia: A Field Guide. (Sainty and Associates PL: NSW, Australia)

Scott WA \& Hallam CJ (2002) Assessing species misidentification rates through quality assurance of vegetation monitoring. Plant Ecology 165: 101-115.

Smith MJ, Ough KM, Scroggie MP, Schreiber ESG \& Kohout M (2009) Assessing changes in macrophyte assemblages with salinity in non-riverine wetlands: a Bayesian approach. Aquatic Botany 90: 137-142.

Spencer C, Robertson A \& Curtis A (1998) Development and testing of a rapid appraisal wetland condition index in south-eastern Australia. Journal of Environmental Management 54: 143159.

USA EPA (2002) Methods for evaluating wetland condition. Introduction to wetland biological assessment. Office of Water, US Environmental Protection Agency, Washington, D.C. EPA822-R-02-014.

Wilhelm G \& Ladd DM (1988) Natural area assessment in the Chicago region. Transactions of the Third North American Wildlife and Natural Resource Conference 3: 361-375.

Manuscript received 04 March 2010, accepted 08 November 2010 